\title{
Gradient Changes in Structural Condition of the B2 Phase of NiTi Surface Layers after Electron-Beam Treatments
}

\author{
Ludmila L. Meisner, 2, a), Ekaterina Yu. Gudimova ${ }^{1,2, b)}$, \\ Marina G. Ostapenko ${ }^{1,3, c)}$, and Aleksandr I. Lotkov ${ }^{1, d)}$ \\ ${ }^{1}$ Institute of Strength Physics and Materials Science SB RAS, Tomsk, 634055, Russia \\ ${ }^{2}$ National Research Tomsk State University, Tomsk, 634050, Russia \\ ${ }^{3}$ National Research Tomsk Polytechnic University, Tomsk, 634050, Russia \\ a) $11 \mathrm{~m} @$ ispms.tsc.ru \\ b) Corresponding author: egu@ispms.tsc.ru \\ c) artifact@ispms.tsc.ru \\ d) lotkov@ispms.tsc.ru
}

\begin{abstract}
Structural conditions of the $\mathrm{B} 2$ phase of the $\mathrm{Ti}_{49.5} \mathrm{Ni}_{50.5}$ alloy surface layers before and after electron-beam treatments (pulse duration $\tau=150 \mu \mathrm{s}$, number of pulses $n=5$, beam energy density $E \leq 20 \mathrm{~J} / \mathrm{cm}^{2}$ ) were studied by X-ray diffraction analysis. Analysis of the X-ray patterns demonstrates that surface layers modified by electron beam treatment contain phase with $\mathrm{B} 2^{\text {surf }}$ structure. It is revealed that the lattice parameter of the $\mathrm{B} 2^{\text {surf }}$ phase in the surface (modified) layer is also higher than the lattice parameter of the $\mathrm{B} 2$ phase in the underlying layer $\left(a_{\mathrm{B} 2}=3.0159 \pm 0.0005\right)$. The values of lattice parameter of phase B2 ${ }^{\text {surf }}$ amounted $a_{\mathrm{B} 2}$ surf $=3.0316 \pm 0.0005 \AA$ and $a_{\mathrm{B} 2}{ }^{\text {surf }}=3.0252 \pm 0.0005 \AA$, for the specimens after electron-beam treatment at $E_{1}=15 \mathrm{~J} / \mathrm{cm}^{2}$ and $E_{2}=20 \mathrm{~J} / \mathrm{cm}^{2}$, respectively. Inflated lattice parameters $a_{\mathrm{B} 2}$ surf are associated with changes in the chemical composition and the presence of residual stresses in the surface region of the samples after electron-beam treatments.
\end{abstract}

Keywords: NiTi, electron-beam treatments, structural phase states, B2 phase, X-ray diffraction analysis

\section{INTRODUCTION}

NiTi-based alloys are widely used in various fields of medicine for many years. These materials have a high corrosion resistance, however, in the case of miniature products which are often less than $1000 \mu \mathrm{m}$ in cross-section, demands on the surface properties of products are greatly increased. One of the promising methods for surface modification of NiTi to improve performance is to use electron beams of low energies. A short electron beam of high energy density produces dynamically varying temperature fields in surface layers thus providing their superfast heating with the result that the layers are melted and then rapidly quenched [1]. It should be beared in mind that electron-beam treatment creates conditions for forming the gradient of the structural states and can lead to a change of physico-mechanical properties not only in the surface but also in the bulk material.

The aim of our work is study of changes in structural condition of the B2 phase of NiTi surface layers after electron-beam treatments.

\section{MATERIALS AND RESEARCH TECHNIQUES}

The $\mathrm{Ti}_{49.5} \mathrm{Ni}_{50.5}$ (further-TiNi) specimens were subjected to pulsed (pulse duration $\tau=150 \mu$ s, number of pulses $n=5)$ surface irradiation by a low-energy high-current $(I=70 \mathrm{~A})$ electron beam with surface melting under the conditions of high vacuum $\left(\sim 10^{-6} \mathrm{~Pa}\right)$ with oilless pumping. The beam energy density was constant $(E=$ const $)$ and

International Conference on Physical Mesomechanics of Multilevel Systems 2014

AIP Conf. Proc. 1623, 407-410 (2014); doi: 10.1063/1.4898968

(C) 2014 AIP Publishing LLC 978-0-7354-1260-6/\$30.00 
was either $E_{1}=15 \mathrm{~J} / \mathrm{cm}^{2}$ or $E_{2}=20 \mathrm{~J} / \mathrm{cm}^{2}$. Thus, there were two groups of specimens the treatment for which differed only in electron beam energy density.

$\mathrm{X}$-ray diffraction (XRD) analysis before and after electron beam treatment was performed at room temperature on a DRON-7 diffractometer (Burevestnik, Russia) in Co-K $\mathrm{K}_{\alpha}$ radiation with a Fe-filter for cutoff of $\beta$-radiation. The phase composition and the structure of surface and deeper layers were analyzed using X-ray diffraction in symmetric (Bragg-Brentano) and asymmetric geometries.

\section{RESULTS AND DISCUSSION}

The initial NiTi specimens at room temperature were in the two-phase state: a B2 phase ( $\sim 95$ vol.\%) and a $\mathrm{Ti}_{2} \mathrm{Ni}$ phase ( $\sim 5 \mathrm{vol} . \%)$. After electron beam treatment of the NiTi specimens at different energy densities $E_{1}=15 \mathrm{~J} / \mathrm{cm}^{2}$, $E_{2}=20 \mathrm{~J} / \mathrm{cm}^{2}$ on X-ray patterns a presence of peaks of B2 and B19' phases and absence of peaks of the $\mathrm{Ti}_{2} \mathrm{Ni}$ phase are observed. The study shows that decreasing of the glancing angle $\alpha$ (decreasing the analyzed layer thickness) decreases the intensity of B19' peaks on the X-ray pattern to the point of almost complete disappearance at the least glancing angle $\alpha=3^{\circ}$.

Figure 1 shows how the position and shape of the $(110)_{\mathrm{B} 2}$ line change after electron beam irradiation of NiTi at $E_{1}=15 \mathrm{~J} / \mathrm{cm}^{2}$ depending on the glancing angle $\alpha$. As can be seen, the position of the $(110)_{\mathrm{B} 2}$ line in the irradiated specimen markedly shifts toward lower angles with decreasing the glancing angle and the shift of this line in the irradiated specimen is much larger than that in the nonirradiated specimen. Because distortions of diffraction patterns, including shifts of X-ray lines, are inevitable in asymmetric geometry, we estimated the instrumental contribution to the observed effect. For this purpose, we used the initial NiTi specimen and measured the position of the diffraction line $(h k l)$ in symmetric geometry, $\theta_{h k l}^{\mathrm{sym}}$, and its position in asymmetric geometry, $\theta_{h k l}^{\mathrm{asym}}$. It was considered that $\Delta \theta_{\text {instr }} \equiv \Delta \theta_{h k l}^{\text {init }}=\theta_{h k l}^{\text {sym }}-\theta_{h k l}^{\text {asym }}$.

The estimates show that in the initial NiTi specimen, $\Delta \theta_{h k l}^{\text {init }} \leq 0.3$ deg for all lines of the B2 phase, and it can thus be taken that for any line of this phase, $\Delta \theta_{\text {instr }} \approx 0.3 \mathrm{deg}$. On the X-ray diffraction patterns in asymmetric geometry, the shift for the NiTi specimens irradiated at $E_{1}=15 \mathrm{~J} / \mathrm{cm}^{2}$ and $E_{2}=20 \mathrm{~J} / \mathrm{cm}^{2}$ was $\Delta \theta_{h k l} \geq 1 \mathrm{deg}$, which is three times larger than the instrumental shift of the line. This means that the shifts of the lines for the NiTi specimens irradiated at $E \leq 20 \mathrm{~J} / \mathrm{cm}^{2}$ owe not only to instrumental factors but also to other factors, e.g., to a change of the chemical composition of the alloy in the modified zone and/or to residual internal stresses in and beneath the irradiated zone.

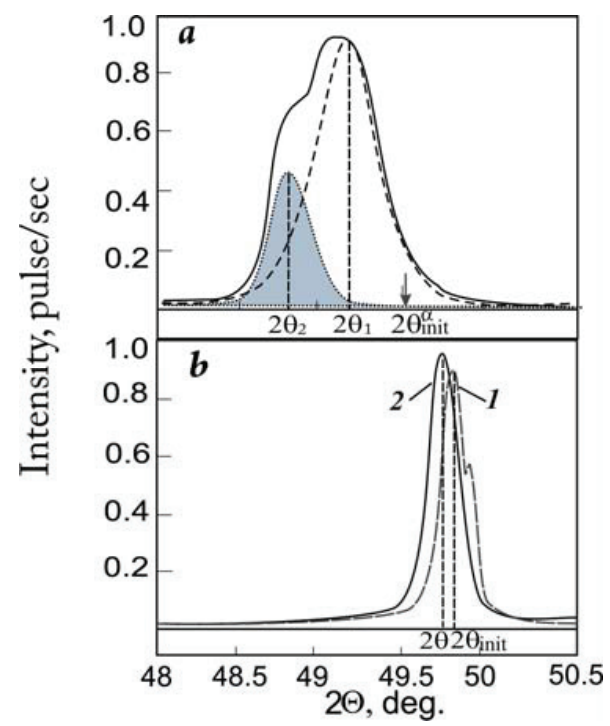

FIGURE 1. Positions and profiles of the $(110)_{\mathrm{B} 2}$ line on X-ray patterns for NiTi before irradiation (dashed line 1 ) and after irradiation at $E_{1}=15 \mathrm{~J} / \mathrm{cm}^{2}$ (solid line 2): asymmetric geometry at glancing angles $\alpha=3^{\circ}$ (a), symmetric geometry (b) 
It is seen from Fig. 1 that the integral $(110)_{\mathrm{B} 2}$ line profile (solid lines in the figure) on the X-ray diffraction patterns is clearly asymmetric. As the glancing angle is decreased, this asymmetry increases, and at $\alpha=3^{\circ}$, it transforms to a doublet (Fig. 1(a)). This diffraction effect is observed for all lines of the B2 phase on the analyzed Xray patterns. Assuming that the observed diffraction effect results from superposition of the X-ray patterns of the single-phase surface layer with $\mathrm{B} 2^{\text {surf }}$ structure modified by electron beam treatment and of its adjacent layer not melted by the electron beam, the lines due to the B2 structure were separated by the Rietveld method [2] into two components: "low-angle" and "high-angle". Figure 1 illustrates the result of this separation of the integral $(110)_{\mathrm{B} 2}$ line into two components with positions of their peaks $2 \theta_{1}$ and $2 \theta_{2}$ for the NiTi specimen irradiated at $E_{1}=15 \mathrm{~J} / \mathrm{cm}^{2}$. Because the intensity of the low-angle components of the lines increases with decreasing the glancing angle $\alpha$, it is reasonable to suppose that these lines belong for $\mathrm{B} 2^{\text {surf }}$ phase, whereas the high-angle components characterize the B2 phase in deeper layers with a structural state of this phase close to the initial state. From this it follows that the lattice parameter of the $\mathrm{B} 2^{\text {surf }}$ phase in the surface (modified) layer is also higher than the lattice parameter of the B2 phase in the underlying (not modified) layer. And finally, the composition of the B $2^{\text {surf }}$ phase is bound to differ from the composition of this phase in the underlying layer, namely, it is bound to be enriched in titanium compared to equiatomic NiTi composition.

In the work, an attempt was made to apply graphical (linear) extrapolation to estimate the lattice parameters of the $\mathrm{B} 2$ and $\mathrm{B} 2^{\text {surf }}$ phases for the NiTi specimens irradiated at $E_{1}=15 \mathrm{~J} / \mathrm{cm}^{2}$ and $E_{2}=20 \mathrm{~J} / \mathrm{cm}^{2}$. To do this, we chose the X-rays patterns obtained for these specimens and initial specimens in asymmetric geometries at a glancing angle $\alpha=3^{\circ}$ and constructed dependences of the B2-cubic lattice parameter on the function $1 / 2\left(\cos ^{2} \theta / \sin \theta+\cos ^{2} \theta / \theta\right)$. For the irradiated NiTi specimens, the parameters $a_{\mathrm{B} 2}$ and $a_{\mathrm{B} 2}{ }^{\text {surf }}$ were calculated from the values $2 \theta_{1}$ and $2 \theta_{2}$, respectively. Figure 2 shows extrapolation diagrams for $a_{\mathrm{B} 2}$ in the nonirradiated NiTi specimen (1); for $a_{\mathrm{B} 2}$ and $a_{\mathrm{B} 2}{ }^{\text {surf }}$ in the NiTi specimen irradiated at $E_{1}=15 \mathrm{~J} / \mathrm{cm}^{2}(2,3)$; and for $a_{\mathrm{B} 2}$ and $a_{\mathrm{B} 2}{ }^{\text {surf }}$ in the NiTi specimen irradiated at $E_{2}=20 \mathrm{~J} / \mathrm{cm}^{2}(4,5)$. It is seen that one can really draw straight lines through the obtained points individually for low-angle and high-angle components of the X-ray lines. This favors our assumption on asymmetry of the B2 lines which is due to the formation of two layers in the near-surface region of the irradiated NiTi specimens: an outer single-phase layer with B2 structure (B2 ${ }^{\text {surf }}$ ) in which the lattice parameter is higher and an adjacent three-phase layer in which the main phase is also B2 but the lattice parameter is lower.

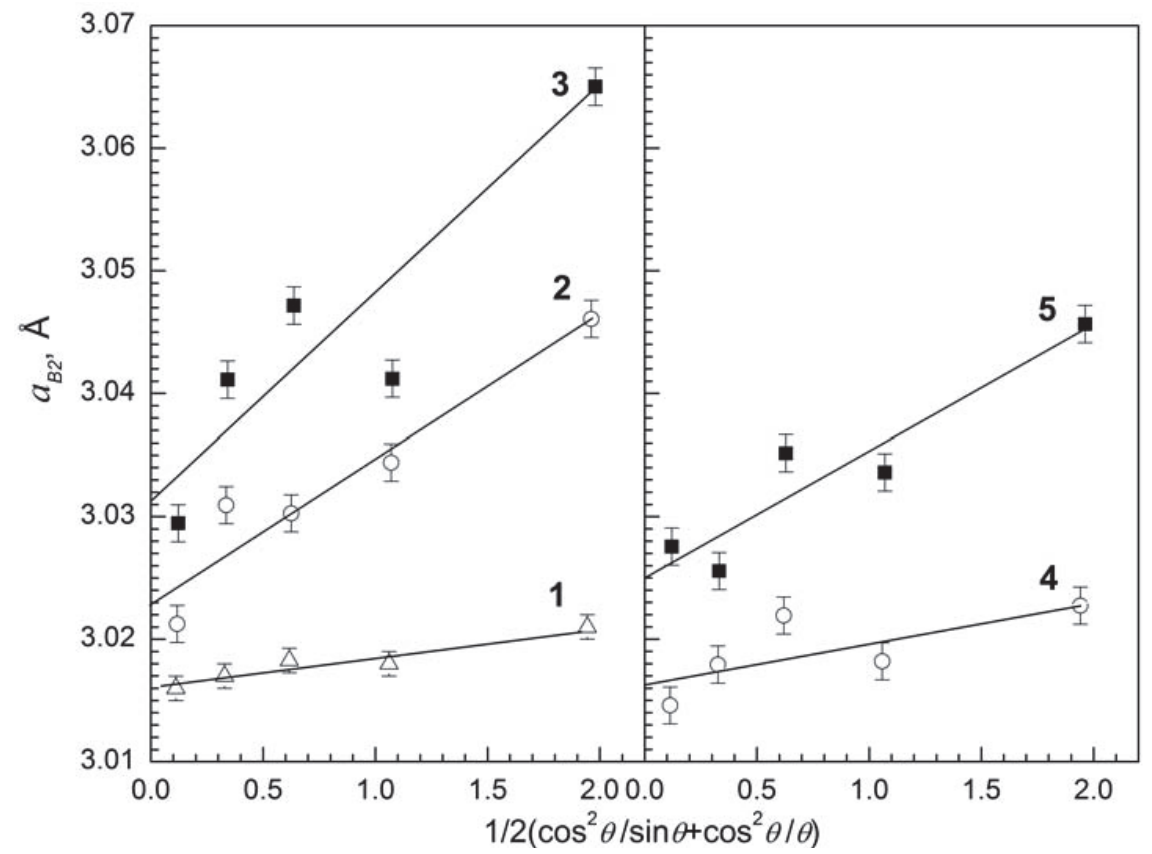

FIGURE 2. Extrapolation dependences of $\mathrm{B} 2$ and $\mathrm{B} 2^{\text {surf }}$ lattice parameters: $a_{\mathrm{B} 2}$ for nonirradiated NiTi $(1) ; a_{\mathrm{B} 2}$ and $a_{\mathrm{B} 2}$ surf for NiTi irradiated at $E_{1}=15 \mathrm{~J} / \mathrm{cm}^{2}(2,3) ; a_{\mathrm{B} 2}$ and $a_{\mathrm{B} 2}{ }^{\text {surf }}$ for NiTi irradiated at $E_{2}=20 \mathrm{~J} / \mathrm{cm}^{2}(4,5)$.

Asymmetric geometry, glancing angle $\alpha=3^{\circ}$ 
From the phase analysis of near-surface layers it follows that after electron beam irradiation with attendant melting of $\mathrm{Ti}_{2} \mathrm{Ni}$ particles and their dissolution in a $\mathrm{Ti}_{49.5} \mathrm{Ni}_{50.5}$-based liquid phase, the solidified $\mathrm{B} 2{ }^{\text {surf }}$ phase is bound to be enriched in titanium. According to the available dependences of the B2 phase lattice parameter on the Ti (or Ni) concentration [3], an increase in the latter increases $a_{\mathrm{B} 2}$ up to its saturation $a_{\mathrm{B} 2 \max } \approx 3.023 \AA$. The high extrapolation values of the $\mathrm{B} 2^{\text {surf }}$ phase lattice parameters $\left(a_{\mathrm{B} 2}{ }^{\text {surf }}=3.0316 \pm 0.0005 \AA, a_{\mathrm{B} 2}{ }^{\text {surf }}=3.0252 \pm 0.0005 \AA\right.$ in the NiTi specimen irradiated at $E_{1}=15 \mathrm{~J} / \mathrm{cm}^{2}$ and $E_{2}=20 \mathrm{~J} / \mathrm{cm}^{2}$, respectively), compared to the above value, are evidence that this phase is enriched in titanium to $c_{\mathrm{Ti}} \geq 50$ at.\% and that the increase in $a_{\mathrm{B} 2}$ is not only due to the change in the chemical composition of the $\mathrm{B} 2{ }^{\text {surf }}$ phase but also to the presence of residual stresses in the surface region of the irradiated specimens.

The problem of estimation of residual stresses arising in NiTi specimens after their electron beam irradiation was discussed in our previous paper [4]. On the example of a NiTi specimen irradiated at $E=20 \mathrm{~J} / \mathrm{cm}^{2}$, it was concluded that the beam-modified surface layer was a concentrator of non-relaxed residual stresses of the first kind which decreased gradiently with depth from the surface. According to the X-ray estimates taken in the cited papers, the maximum residual stresses $\sigma \approx 500 \mathrm{MPa}$ localized in the modified zone, and $\sigma$ in its adjacent layers was no greater than $\sim 100 \mathrm{MPa}$.

The enrichment in titanium with respect to the equiatomic NiTi phase composition is bound to shift the temperature intervals of direct and reverse martensite transformations by 30-50 degree toward higher values compared to their temperatures in $\mathrm{Ti}_{49.5} \mathrm{Ni}_{50.5}$ [3]. Consequently, the $\mathrm{B} 19^{\prime}$ martensite amount in the region of the $\mathrm{B} 2^{\text {surf }}$ phase as well as in its adjacent layer at $T_{\text {room }}=293 \mathrm{~K}$ is bound to be sufficiently large. However, in the NiTi specimens irradiated at $E \leq 20 \mathrm{~J} / \mathrm{cm}^{2}$, the $\mathrm{B} 19^{\prime}$ phase is present only in small amount and at some depth from the irradiated surface.

\section{CONCLUDING REMARKS}

In the irradiated NiTi specimens, the modified outer layer (melted and quenched) is free from $\mathrm{Ti}_{2} \mathrm{Ni}$ particles which are present in large amount in the specimens before treatment. The dissolution of $\mathrm{Ti}_{2} \mathrm{Ni}$ particles in the liquid phase of near-equiatomic composition results in a $\mathrm{B} 2^{\text {surf }}$ phase whose lattice parameter is higher than that in the initial B2 phase. The lattice parameters of the $\mathrm{B} 2^{\text {surf }}$ phase are $a_{\mathrm{B} 2}{ }^{\text {surf }}=3.0316 \pm 0.0005 \AA$ and $a_{\mathrm{B} 2}{ }^{\text {surf }}=3.0252 \pm$ $0.0005 \AA$ for low-energy high-current electron beam treatment at $E_{1}=15 \mathrm{~J} / \mathrm{cm}^{2}$ and $E_{2}=20 \mathrm{~J} / \mathrm{cm}^{2}$, respectively.

From the values of the $\mathrm{B} 2^{\text {surf }}$ lattice parameter obtained by graphical extrapolation it follows that after a fivefold "melting-quenching" cycle, the Ti concentration in this phase increases to $c_{\mathrm{Ti}} \geq 50.0$ at.\% compared to the initial B2 phase in which the Ti concentration is $c_{\mathrm{Ti}}=49.5$ at.\%. Because the $\mathrm{B} 2$ phase of double Ti-Ni composition with $c_{\mathrm{Ti}} \geq 50.0$ at.\% experiences $\mathrm{B} 2 \rightarrow \mathrm{B} 19^{\prime}$ martensite transformation at $M_{\mathrm{s}}$ by $30-50$ degree higher than $T_{\text {room }}=293 \mathrm{~K}$, the martensite state would be expected to dominate in the outer layer of the irradiated NiTi specimen. The assumption that the barrier to $\mathrm{B} 2 \rightarrow \mathrm{B} 19^{\prime}$ martensite transformation in the NiTi specimens irradiated $E \leq 20 \mathrm{~J} / \mathrm{cm}^{2}$ is the presence of high inhomogeneous residual stresses varying with depth from the irradiated surface requires further research.

The authors are thankful to Prof. N. N. Koval, Head of Laboratory of Plasma Emission Electronics of IHCE SB RAS, for help in organizing the electron beam treatment of NiTi specimens and to A. D. Teresov, Lead Electronic Engineer, for conduction of the treatment.

The work was performed under project of SB RAS No. III.23.2.1 and supported by Scholarship Fund of the President of the Russian Federation (SP-236.2012.4).

\section{REFERENCES}

1. V. P. Rotshtein, Yu. F. Ivanov, and A. B. Markov, Review In Book: Materials Surface Processing By Directed Energy Techniques, edited by Y. Pauleau (Elsevier, Amsterdam, 2006), p. 205.

2. H. M. Rietveld, J. Appl. Cryst. 2, 65 (1969).

3. V. N. Grishkov and A. I. Lotkov, Fiz. Met. Metalloved. 60(2), 351 (1985).

4. L. L. Meisner, A. A. Lotkov, M. G. Ostapenko, and E. Yu. Gudimova, Appl. Surf. Sci. 280, 398 (2013). 